\title{
Fundamental Analysis of a Ferrite Permanent Magnet Axial Gap Motor with Coreless Rotor Structure
}

\author{
Kazuya Chiba ${ }^{* a)}$ \\ Student Member, \\ Shinji Chino* \\ Non-member \\ Masatsugu Takemoto* Member, \\ Satoshi Ogasawara* \\ Senior Member
}

(Manuscript received Jan. 9, 2013, revised July 23, 2013)

\begin{abstract}
Rare earth permanent magnets (PMs) with a large energy product are generally used in the traction motors of hybrid electric vehicles. However, developing rare-earth-free motors is necessary because of problems with rare earth materials, such as increasing prices and difficulty in their supply. This paper introduces such a rare-earth-free motor: a ferrite PM axial gap motor with a coreless rotor structure. The motor structure and the results of three-dimensional finite element analysis are described in detail.
\end{abstract}

Keywords: axial gap motor, coreless rotor structure, rare-earth-free motors, hybrid electric vehicles

\section{Introduction}

Interest in environmental problems such as global warming is increasing every year. Hybrid electric vehicles (HEVs) are expected to reduce carbon dioxide emissions - one of the causes of environmental problems. In HEVs, permanent magnet synchronous motors (PMSMs) are generally used because of their small size, high power, and high efficiency. Rare earth permanent magnets (PMs) with a large energy product are generally used for PMSMs ${ }^{(1)-(4)}$. However, it is necessary to develop rare-earth-free motors for HEV traction motors because of several problems such as increasing prices and the uncertain supply of the required rare earth materials - neodymium and dysprosium.

The Toyota Prius is a well-known HEV. The total axial length of the traction motor of the third-generation Prius is only $69 \%$ of that of the second-generation model. Traction motors with flatter shapes will be required in future generations; hence, it is important to develop appropriately shaped rare-earth-free motors. This paper sets the $60 \mathrm{~kW}$ traction motor in the third-generation Toyota Prius as its development target.

Radial gap motors are generally used as HEV traction motors. In radial gap motors, the ratio of the coil end to the motor volume increases as the motor shape flattens, thereby decreasing torque density because the coil end generates no torque. However, the dead space at the coil end resulting from the motor flattening is small in axial gap motors, and hence, high torque densities can be expected ${ }^{(1)-(14)}$. Therefore, we propose a motor that takes the structure of an axial gap motor and replaces the rare earth PMs with ferrite PMs.

We had proposed a ferrite PM axial gap motor with a segmented rotor structure in a previous paper ${ }^{(1)}$. In this motor,

a) Correspondence to: Kazuya Chiba. E-mail: chiba@sfc.ssi.ist. hokudai.ac.jp

* Department of Information Science and Technology, Hokkaido University

Kita 14, Nishi 9, Kita-ku, Sapporo 060-0814, Japan soft magnetic composite (SMC) cores are installed inside a rotor to utilize reluctance torque. In contrast, the rotor in the motor proposed in this paper is made up of ferrite PMs and a non-magnetic rotor support component without the SMC cores. Hence, the proposed motor has a coreless rotor structure that attains high efficiency by reducing iron loss owing to its decreased magnetic flux density.

This paper introduces a ferrite PM axial gap motor with a coreless rotor structure as an example of a rare-earth-free motor suitable for flat shapes. Three-dimensional finite element analysis (3D-FEA) confirms that the proposed motor can achieve a maximum torque of $207 \mathrm{Nm}$, a constant output of $60 \mathrm{~kW}$, and a maximum efficiency of $97 \%$. This performance is equivalent to that of the $60 \mathrm{~kW}$ traction motor in the third-generation Toyota Prius.

\section{Structure of a Ferrite Axial Gap Motor with a} Coreless Rotor Structure

Table 1 lists the specifications of our target motor: the $60 \mathrm{~kW}$ traction motor that employs rare earth magnets and is used in the third-generation Toyota Prius. The motor volume including the coil end, as measured in our laboratory, is $5.91 \mathrm{~L}$, the maximum torque is $207 \mathrm{Nm}$, the constant output power is $60 \mathrm{~kW}$, and the maximum efficiency is $97 \%$. Here, the efficiency of the traction motor in the third-generation Toyota Prius was calculated using two-dimensional finite element analysis (2D-FEA). We intend to develop a motor that has similar performance specifications but does not use rare earth materials.

Figure 1 shows an outline of the proposed motor: an axial gap motor with an internal rotor and an external stator structure, in which a single rotor is sandwiched by two stators. The volume of the proposed motor is the same as that of the target motor.

Figure 2 shows the rotor configuration of the proposed motor with 10 poles. The rotor is constructed by installing only ferrite magnets on a rotor support component with nonmagnetic steel. The coreless rotor structure does not use 
Table 1. Target value of a ferrite PM axial gap motor with coreless rotor structure

\begin{tabular}{c|c} 
& Target value \\
\hline Max. power & $60 \mathrm{~kW}$ \\
\hline Volume (including the coil end) & $5.91 \mathrm{~L}$ \\
\hline Max. torque & $207 \mathrm{Nm}$ \\
\hline Max. torque density & $35.01 \mathrm{Nm} / \mathrm{L}$ \\
\hline Base rotational speed & $2768 \mathrm{r} / \mathrm{min}$ \\
\hline Max. rotational speed & $13900 \mathrm{r} / \mathrm{min}$ \\
\hline Max. efficiency & $97 \%$ \\
\hline Max. current density & $\begin{array}{c}20 \text { Arms } / \mathrm{mm}^{2} \\
(\text { surmised value) }\end{array}$
\end{tabular}

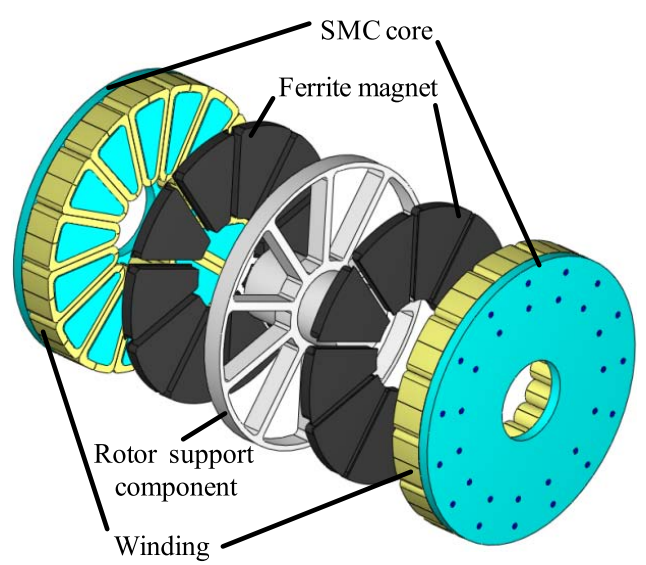

Fig. 1. Outline of a ferrite PM axial gap motor with coreless rotor structure

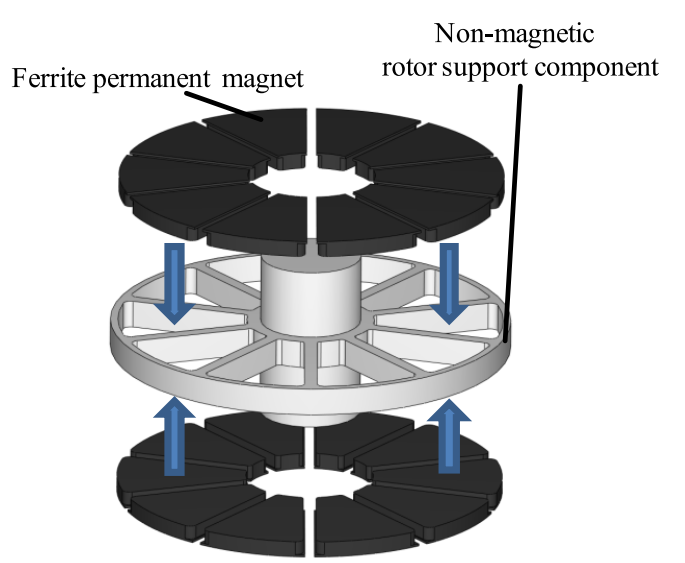

Fig. 2. Rotor configuration of a coreless rotor structure

magnetic materials such as the SMC core. The ferrite magnets are magnetized parallel to the axial direction and the direction of magnetization alternates at each magnet segment. The proposed motor is a non-salient pole machine in which the self-inductance of the d-axis and q-axis are equal because the rotor is a surface PM with a coreless rotor structure. Hence, the magnetic torque can be utilized exclusively and efficiency improvements can be expected from the reduced iron loss because the coreless rotor structure can
Table 2. Specification of a ferrite PM axial gap motor with coreless rotor structure

\begin{tabular}{c|c}
\hline Number of poles & 10 \\
\hline Number of slots & 15 \\
\hline Outer diameter of stator & $264 \mathrm{~mm}$ \\
\hline Inner diameter of stator & $74 \mathrm{~mm}$ \\
\hline Stator height & $42.25 \mathrm{~mm}$ \\
\hline Outer diameter of rotor & $264 \mathrm{~mm}$ \\
\hline Rotor thickness & $21 \mathrm{~mm}$ \\
\hline Total motor axial length & $108 \mathrm{~mm}$ \\
\hline Diameter of shaft & $66 \mathrm{~mm}$ \\
\hline Air gap & $1.25 \mathrm{~mm}$ \\
\hline Volume (including the coil end) & $5.91 \mathrm{~L}$ \\
\hline Max. current density & $18.4 \mathrm{Arms} / \mathrm{mm}{ }^{2}$ \\
\hline Rotor support component & $\begin{array}{c}\text { Japan Steel Works, Ltd. } \\
18 \% \text { Mn steel }\end{array}$ \\
\hline Ferrite permanent magnet & $\begin{array}{c}\text { Hitachi Metals, Ltd. } \\
\text { NMF-12G+ }\end{array}$ \\
\hline Iron core & Kobe Steel, Ltd. \\
SMC core
\end{tabular}

reduce magnetic flux density.

This rotor structure resists irreversible demagnetization, which is a problem with ferrite magnets, because it is possible to maximize the thickness of the ferrite magnet within the limited rotor dimensions ${ }^{(1)}$.

A stator with 15 slots is constructed using SMC cores and windings. Specifically, three-phase 10-pole concentrated windings are wound around the 15 stator teeth.

Table 2 lists the specifications of the proposed motor. The outer diameter of the stator is $264 \mathrm{~mm}$, and the total axial length between the backs of the two stators is $108 \mathrm{~mm}$. Accordingly, the volume (including the coil end) of the proposed motor is $5.91 \mathrm{~L}$, which is equivalent to that of the target motor. The gap length on one side of the proposed motor is $1.25 \mathrm{~mm}$. The exact form of each part is determined such that the magnetic torque is maximized for the restricted motor size. The rotor support component uses $18 \% \mathrm{Mn}$ steel (Japan Steel Works, Ltd.), which is a non-magnetic material, and the ferrite magnet uses NMF-12G+ (Hitachi Metals, Ltd.). The stator uses an SMC core (Kobe Steel, Ltd.). The tensile strength and yield strength of the $18 \%$ Mn steel depend on the nitrogen content ${ }^{(15)}$. We use $18 \% \mathrm{Mn}$ steel with a yield strength of $415 \mathrm{MPa}$. In addition, the conductivity of $18 \% \mathrm{Mn}$ steel is $1320000 \mathrm{~S} / \mathrm{m}$, and this value is used for the eddy current loss calculation. The rare earth material, lanthanum, is used in the ferrite magnet NMF-12G+. Because the problems arising from the use of neodymium and dysprosium, which are used in rare earth PMs, do not arise in the case of lanthanum, the use of lanthanum is preferred in this study. Figure 3 and Fig. 4 show the magnetic properties of $\mathrm{NMF}-12 \mathrm{G}+$ and the SMC core, respectively. These magnetic properties are used for 3D-FEA.

Additionally, the copper fill factor of the proposed motor is $57.55 \%$, whereas that of the target motor is $56.40 \%$. The copper fill factor of the proposed motor approximately corresponds to that of the target motor. The thickness of an insulation sheet used for the slots is not considered while calculating the copper fill factor of both motors. 


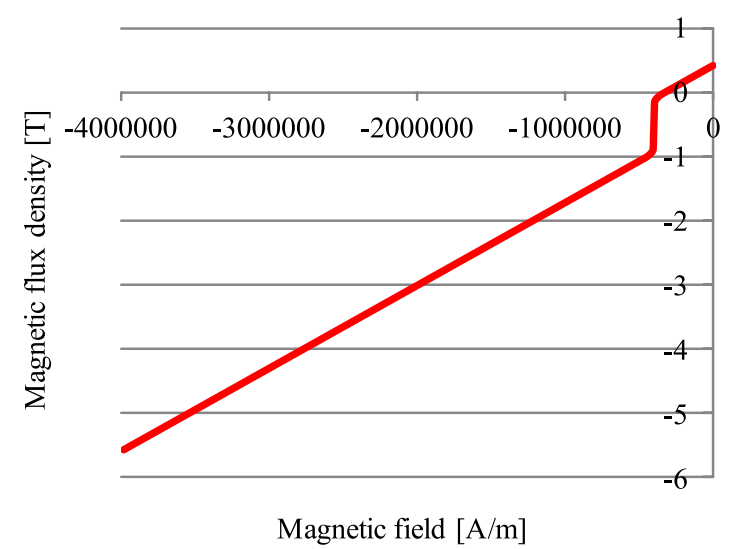

Fig. 3. Magnetic property of NMF-12G+

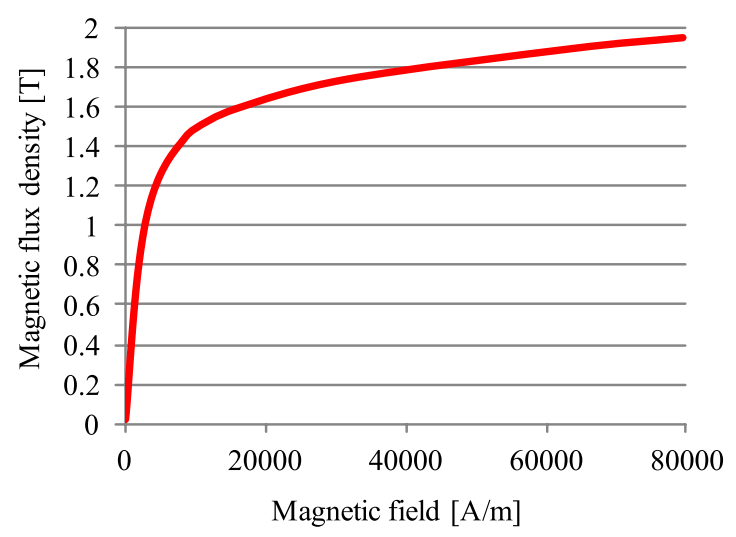

Fig. 4. Magnetic property of SMC core

\section{Characteristics of the Proposed Motor}

3.1 Torque Characteristics 3D-FEA was carried out to confirm the validity of the proposed motor. The analysis conditions were as follows. The base rotational speed was $2800 \mathrm{r} / \mathrm{min}$, which is almost equal to the base rotational speed of $2768 \mathrm{r} / \mathrm{min}$ of the target motor. The magnet temperature was constant at $75^{\circ} \mathrm{C}$. The current phase angle was $0^{\circ}$ because the proposed motor generates only magnetic torque. To evaluate the proposed motor, 2D-FEA was also performed for the target motor. For the analysis, the rotational speed was adjusted to $2800 \mathrm{r} / \mathrm{min}$ to match that of the proposed motor, the magnet temperature was constant at $75^{\circ} \mathrm{C}$, and the current phase angle was $50^{\circ}$ - conditions at which the target motor generated the maximum torque.

Figure 5 shows the instantaneous torque waveform under the maximum current density of $18.4 \mathrm{Arms} / \mathrm{mm}^{2}$ and the above analysis conditions. The maximum average torque of the proposed motor is $207.65 \mathrm{Nm}$, the same as that of the target motor. Hence, the output power is $60.89 \mathrm{~kW}$ at the base rotational speed, and the proposed motor can provide an equal output power at the same volume as the target motor with rare earth magnets.

Figure 6 compares the torque ripple ratio between the proposed and target motors. In Fig. 6, the maximum average torque of each motor is standardized as 1 p.u. for simplicity of comparison. The torque ripple ratios of the proposed motor and the target motor are $10.73 \%$ and $12.45 \%$, respectively.

Figure 7 shows the cogging torque waveform of both

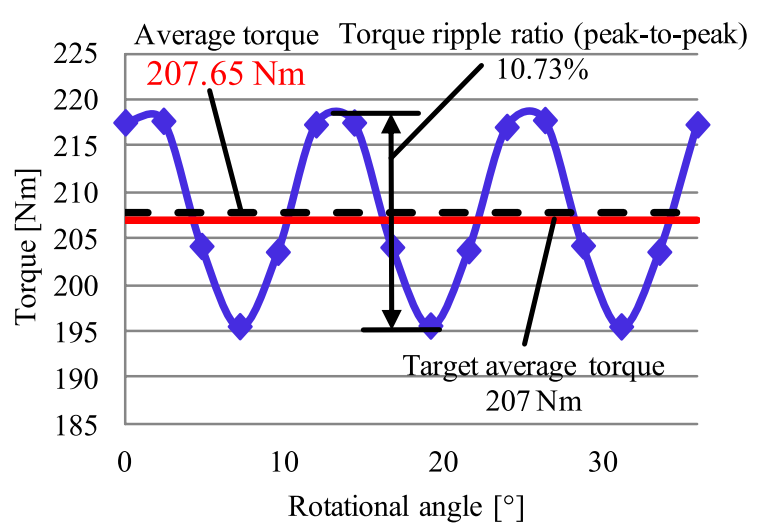

Fig. 5. Relation of instantaneous torque and rotational angle at maximum current density

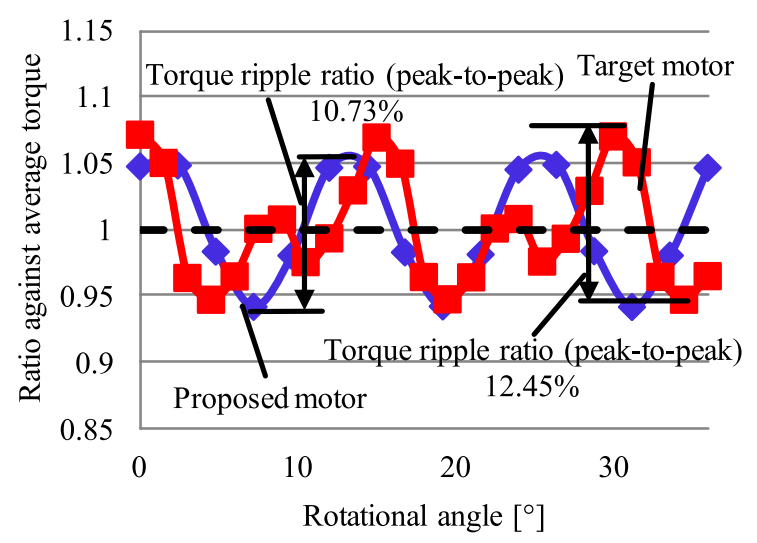

Fig. 6. Comparison of torque ripple ratio between the proposed motor and the target motor at maximum current density

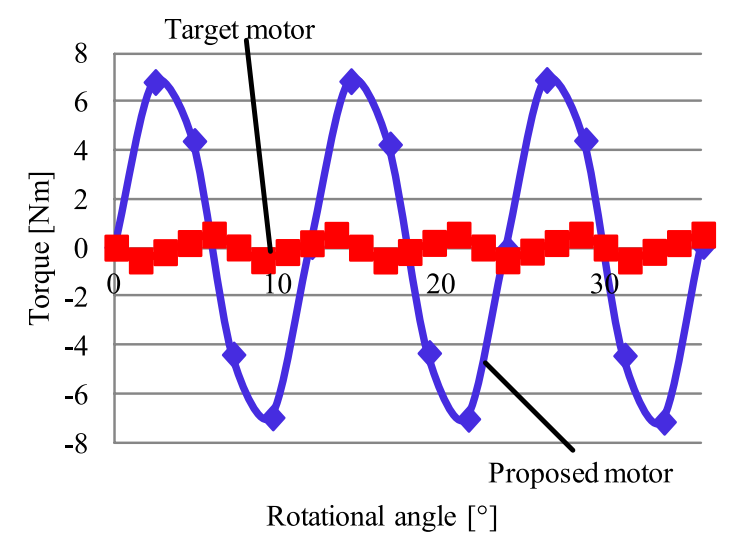

Fig. 7. Comparison of cogging torque between the proposed motor and the target motor

motors under zero torque load. The cogging torques of the proposed motor and the target motor are $\pm 7.03 \mathrm{Nm}$ and $\pm 0.53 \mathrm{Nm}$, respectively. The cogging torque of the proposed motor is greater than that of the target motor. Although the cogging torque of the proposed motor is only $3.4 \%$ of the maximum average torque, in future research, we hope to suppress the cogging torque by optimizing the motor shape.

3.2 Comparison of the Flux Density Distribution

The proposed motor uses a coreless rotor structure to reduce the magnetic flux density. Here, the flux density distribution of both motors is compared to validate the concept of 


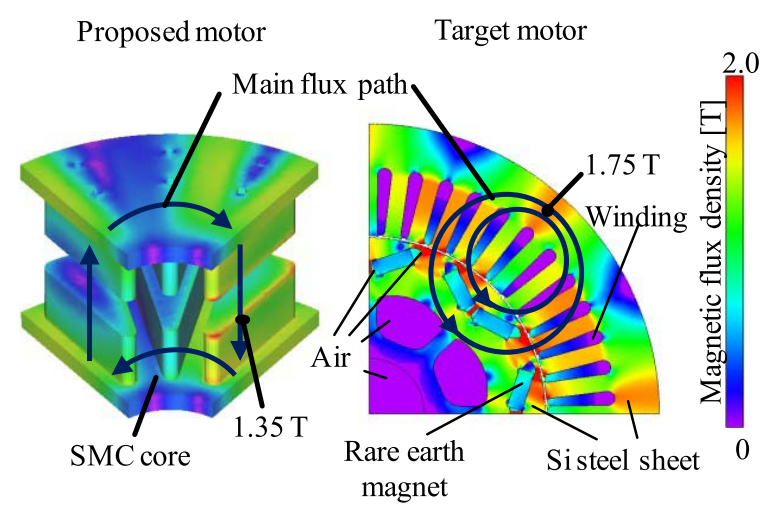

Fig. 8. Comparison of magnetic flux density distribution between the proposed motor and the target motor at maximum current density

the coreless rotor structure.

Figure 8 shows the flux density distribution of both motors. The proposed motor is shown using a $1 / 5$ cut model of only the stator by hiding the rotor, and the target motor is shown with a $1 / 4$ cut model. The magnetic flux densities on the main flux path of the proposed motor and the target motor are $1.35 \mathrm{~T}$ and $1.75 \mathrm{~T}$, respectively. Figure 8 shows that the magnetic flux density of the proposed motor is low compared to that of the target motor.

3.3 Irreversible Demagnetization We performed demagnetization analysis for the proposed motor to evaluate the irreversible demagnetization of the ferrite magnets. Demagnetization of rare earth magnets tends to occur at high temperatures, but it can also happen at low temperatures in ferrite magnets. Therefore, the analysis conditions were set as follows. The temperature was $-40^{\circ} \mathrm{C}$ and $75^{\circ} \mathrm{C}$ for ferrite magnets and $150^{\circ} \mathrm{C}$ for rare earth magnets. The current phase angle was constant at $90^{\circ}$, and the rotational angle was fixed at $0^{\circ}$.

Figure 9 shows the appearance of irreversible demagnetization in the ferrite magnets in the proposed motor for the maximum current density. In Fig. 9, the temperature of the ferrite magnets is $-40^{\circ} \mathrm{C}$. In spite of this worst-case analysis condition, irreversible demagnetization does not increase drastically in the ferrite magnets of the proposed motor. Hence, irreversible demagnetization is not considered to be a significant problem at the maximum current density in the proposed motor.

The reduction ratio of the U-phase flux linkage is used as an index to assess the irreversible demagnetization of the magnet quantitatively. The reduction ratio of the U-phase flux linkage is derived from $\Psi_{m A}$ and $\Psi_{m B}$, the U-phase flux linkages generated by the ferrite PMs before and after conduction, respectively. Thus, the reduction ratio $\delta$ of the $\mathrm{U}-$ phase flux linkage is as follows:

$$
\delta=\frac{\Psi_{m A}-\Psi_{m B}}{\Psi_{m A}} \times 100[\%],
$$

Figure 10 shows the reduction ratio of the U-phase flux linkage in both motors at each current density, derived from $\mathrm{Eq}$ (1). Here, the reduction ratio of the U-phase flux linkage in the proposed motor is shown for magnet temperatures of $-40^{\circ} \mathrm{C}$ and $75^{\circ} \mathrm{C}$, and the reduction ratio of the U-phase flux

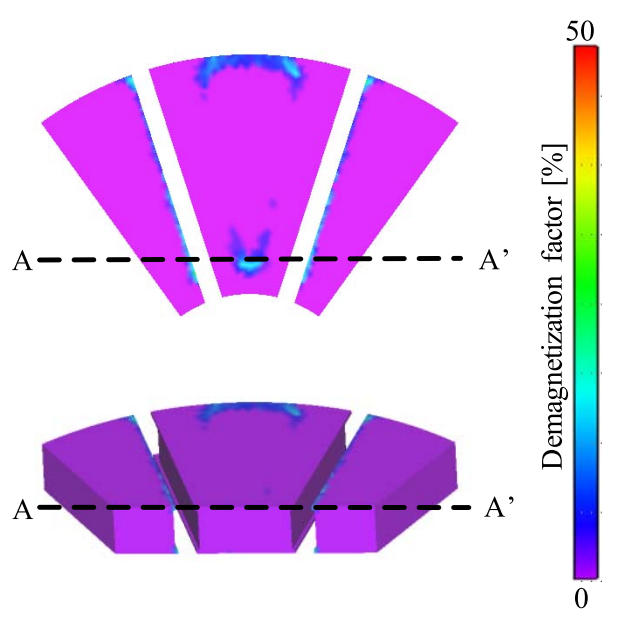

Fig. 9. Analysis results about the irreversible demagnetization of ferrite permanent magnets in the proposed motor

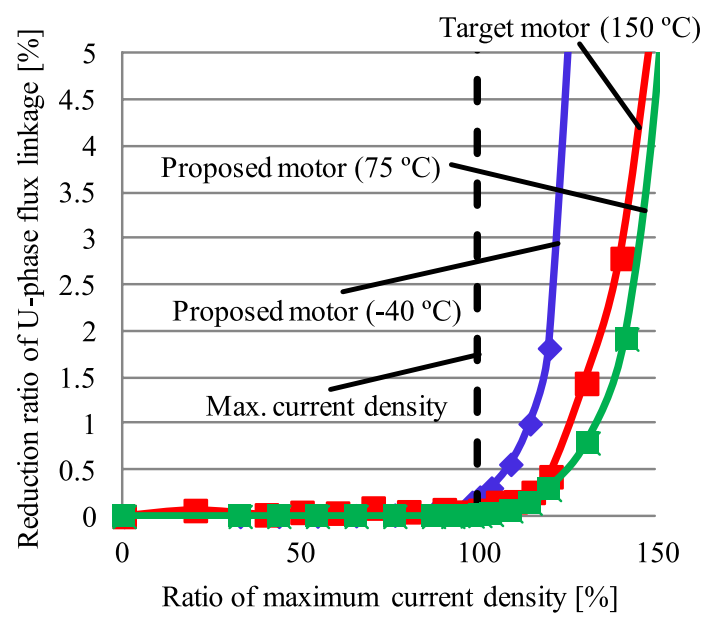

Fig. 10. Comparison of the transitions of the reduction ratio of U-phase flux linkage in both motors

linkage in the target motor is shown for a magnet temperature of $150^{\circ} \mathrm{C}$. At the maximum current density, the reduction ratio of the U-phase flux linkage is less than $0.5 \%$ in each curve. Although irreversible demagnetization is more likely in the proposed motor at $-40^{\circ} \mathrm{C}$ than in the target motor at $150^{\circ} \mathrm{C}$, the U-phase flux linkage reduction of the proposed motor at $75^{\circ} \mathrm{C}$ is almost equal to that of the target motor at $150^{\circ} \mathrm{C}$. In fact, the operating time of $\mathrm{HEVs}$ under $-40^{\circ} \mathrm{C}$ conditions is quite short because the motor temperature, including that of the magnet, increases immediately. Hence, in terms of irreversible demagnetization, the performance of the proposed motor is almost the same as that of the target motor.

3.4 Von Mises Stress Another important investigation is the endurance of the proposed motor against von Mises stress. Figure 11 shows the maximum von Mises stress in the rotor support component at each rotational speed. The yield strength of the $18 \% \mathrm{Mn}$ steel used in the rotor support component is $415 \mathrm{MPa}$. At $7500 \mathrm{r} / \mathrm{min}$, the maximum von Mises stress is $280.1 \mathrm{MPa}$. At this point, the safety ratio with respect to the yield strength of $18 \% \mathrm{Mn}$ steel is 1.48 . Accordingly, $7500 \mathrm{r} / \mathrm{min}$ is set as the maximum rotational speed of the proposed motor as a margin against stress.

Figure 12 shows the distribution of the von Mises stress 


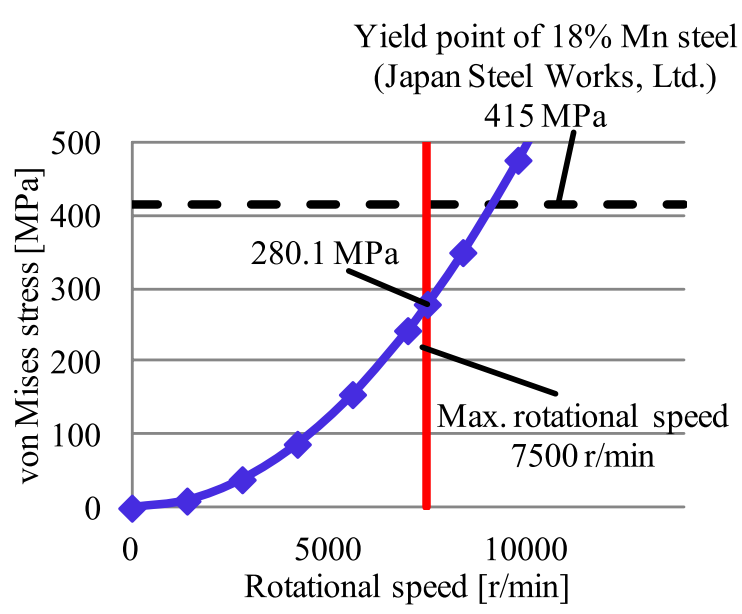

Fig. 11. Relation of rotational speeds and von Mises stress

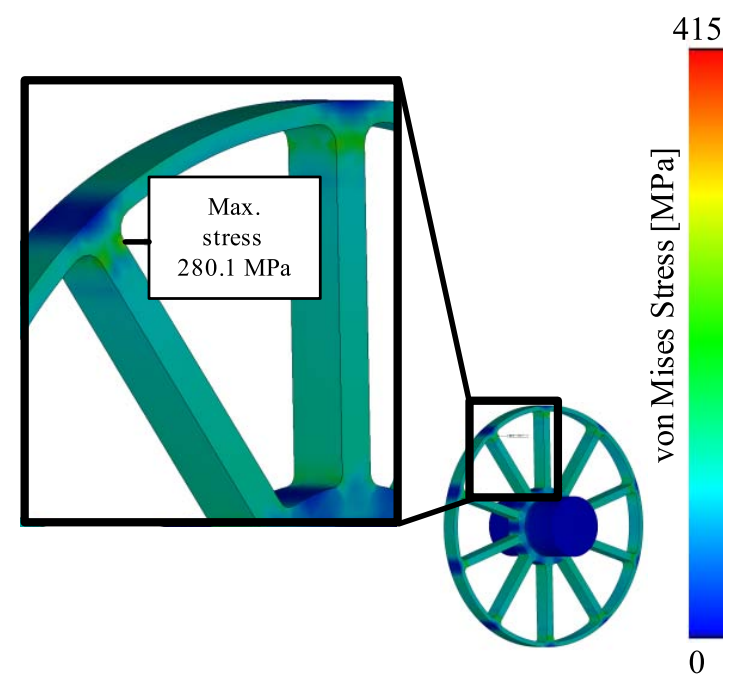

Fig. 12. Analysis results about the von Mises stress in the proposed motor at $7500 \mathrm{r} / \mathrm{min}$

at the maximum rotational speed of $7500 \mathrm{r} / \mathrm{min}$. The von Mises stress in the rotor support component is concentrated at the boundary between the pillars extending radially from the center and the outer circular ring. As designed, the proposed motor's rotational speed cannot be increased to the target motor's maximum speed of $13900 \mathrm{r} / \mathrm{min}$. Therefore, the proposed motor is suitable for use as a traction motor in a parallel hybrid system that rotates at the same speed as the engine because the engine rotational speed is generally $7500 \mathrm{r} / \mathrm{min}$ or less.

3.5 Efficiency This section compares and discusses the efficiencies of the proposed and target motors. The efficiency of the proposed motor is derived from the following equation:

$$
\eta=\frac{P_{\text {OUT }}}{P_{\text {OUT }}+W_{C}+W_{I R}+W_{I S}} \times 100[\%], \cdots \cdots \cdots
$$

where $P_{\text {OUT }}$ is the output power, $W_{C}$ is the copper loss, $W_{I R}$ is the eddy current loss that is generated in the rotor support component, and $W_{I S}$ is the iron loss that is generated in the SMC cores.

In (2), the eddy current loss of the ferrite magnets is negligible, and therefore, it is not considered.

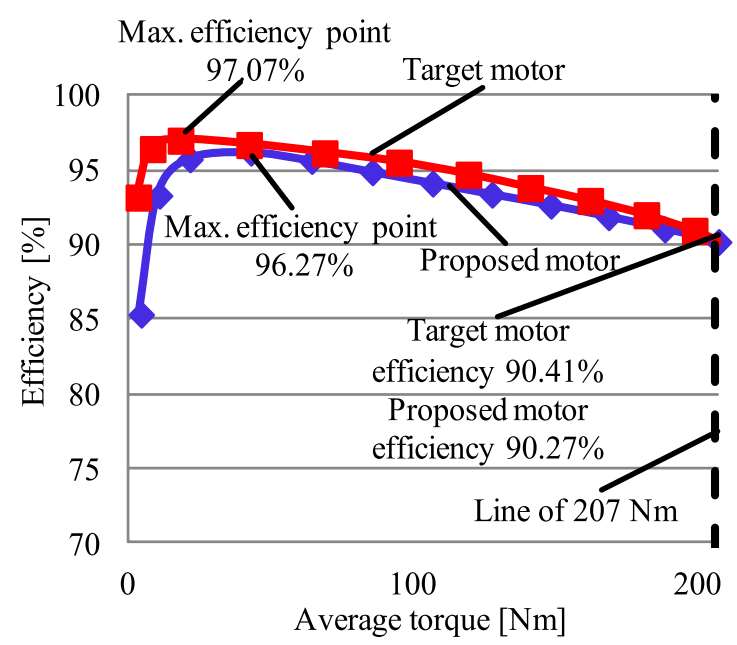

Fig. 13. Relation of average torque and efficiency at base rotational speed

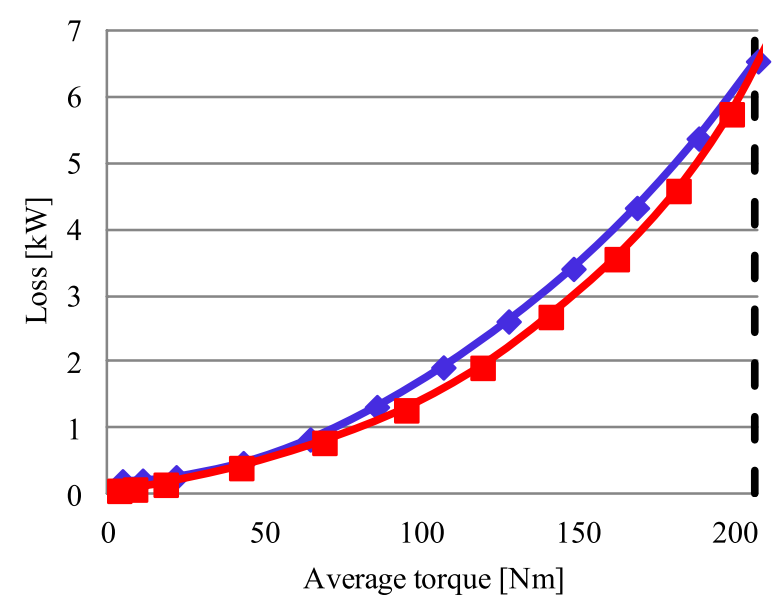

Fig. 14. Relation of average torque and total loss at base rotational speed

Figure 13 shows the comparison of the efficiencies of the proposed and target motors at the base rotational speed. The maximum efficiencies of the proposed and target motors are $96.27 \%$ and $97.07 \%$, respectively. The maximum efficiency of the target motor is only $0.8 \%$ higher than that of the proposed motor, and the efficiencies at the maximum average torque are $90.27 \%$ and $90.41 \%$, respectively, making the efficiencies of both motors almost equal.

Figure 14 shows the total loss in both motors at the base rotational speed. The total loss in the proposed motor is slightly higher than that in the target motor, resulting in the efficiency gap shown in Fig. 13.

Figure 15 shows the copper and iron losses in both motors at the base rotational speed to show the small difference in the total loss in both motors. While the copper loss in the proposed motor is slightly lower than that in the target motor owing to its concentrated winding structure, the iron loss in the proposed motor is higher than that in the target motor. However, the total loss in both motors is almost the same because the copper loss dominates the total loss.

We investigate the iron loss in the proposed motor more closely because it is much greater than that in the target motor. 


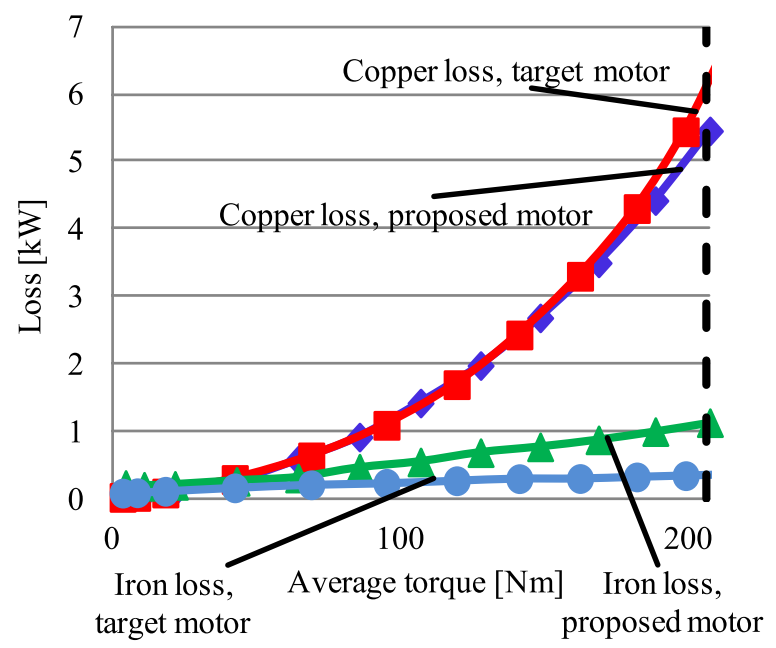

Fig. 15. Relation of copper loss and iron loss at base rotational speed

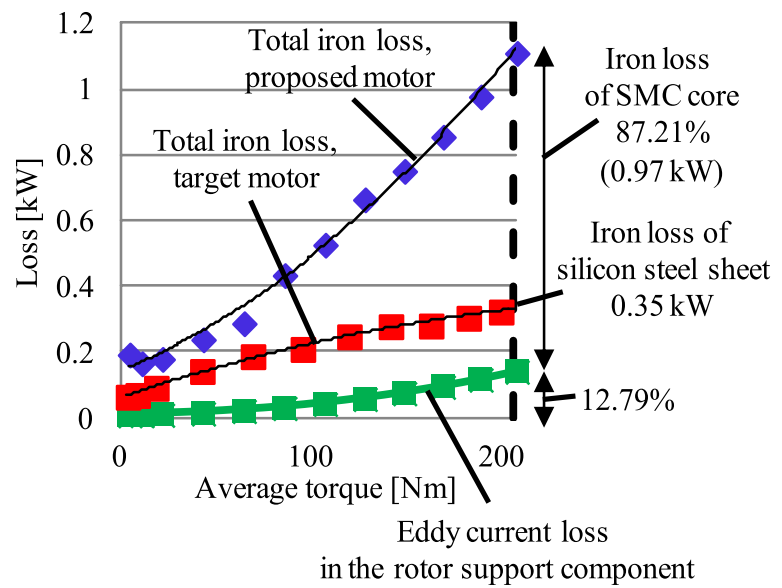

Fig. 16. Relation of total iron loss and eddy current loss in the rotor support component at base rotational speed

Figure 16 shows the iron loss factors in both motors. In the proposed motor, the eddy current loss in the rotor support component is $12.79 \%$ of the total loss and the iron loss in the stator SMC core is $87.21 \%$. While the iron loss in the SMC core of the proposed motor is $0.97 \mathrm{~kW}$ when it is generating the maximum torque, the iron loss in the target motor's silicon steel sheet is $0.35 \mathrm{~kW}$. Figure 17 shows the comparison of the data on the iron loss in the SMC core and the silicon steel sheet at the base frequency vicinity of $200 \mathrm{~Hz}$. This iron loss data is used for the iron loss calculation. Eddy current loss and hysteresis loss are included in the data on the iron loss in the SMC core. The density of the iron loss in the SMC core is much greater than that in the silicon steel sheet. In addition, at other frequencies, the iron loss density in the SMC core is greater than that in the silicon steel sheet. Thus, the result shown in Fig. 16 is due to the material performance differences between the SMC core and the silicon steel sheet. The iron loss reduction in the coreless rotor structure is higher as compared to that in the conventional rotor structure, causing high magnetic flux density. However, the reduction of iron loss in the proposed motor is insufficient in comparison with that in the silicon steel sheet of the target motor. Hence, improving the motor shape to reduce the eddy current loss in the

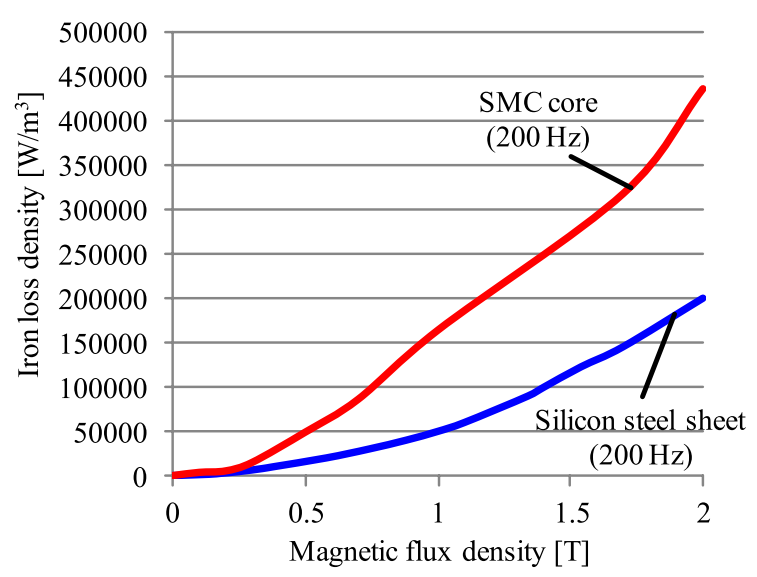

Fig. 17. Comparison of iron loss density versus magnetic flux density between the SMC core and the silicon steel sheet at $200 \mathrm{~Hz}$

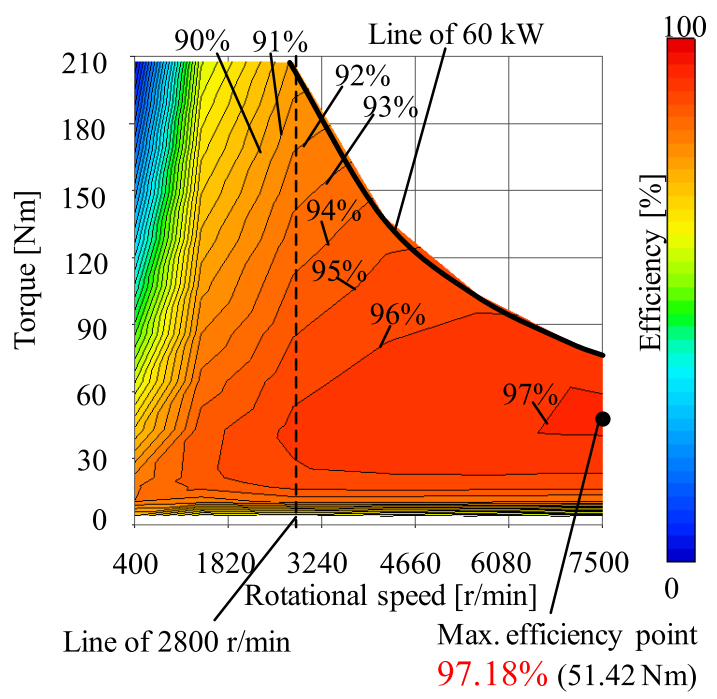

Fig. 18. Efficiency map of the proposed motor

rotor support component and the iron loss in the stator SMC core is required to increase efficiency.

Figure 18 shows an efficiency map, obtained through 3DFEA, for the complete operating range of the proposed motor. The thick line in Fig. 18 shows the torque curve, which can achieve a constant $60 \mathrm{~kW}$ output. In spite of the surface PM and coreless rotor structure, $60 \mathrm{~kW}$ of constant output power is achievable in the driving range, from the base rotational speed of $2800 \mathrm{r} / \mathrm{min}$ to the maximum rotational speed of $7500 \mathrm{r} / \mathrm{min}$. In addition, the efficiency exceeds $90 \%$ over a very wide range. The maximum efficiency of the proposed motor is $97.18 \%$ for an average torque of $51.42 \mathrm{Nm}$ at $7500 \mathrm{r} / \mathrm{min}$. The maximum efficiency of the proposed motor is equal to that of the target motor. Particularly remarkable is the high efficiency at rotational speeds higher than the base rotational speed. Figure 19 shows the transition of the iron loss, copper loss, and total loss in the proposed motor, at a constant output power of $60 \mathrm{~kW}$, in the driving range between $2800 \mathrm{r} / \mathrm{min}$ and $7500 \mathrm{r} / \mathrm{min}$. In spite of the constant output power, the iron loss, copper loss, and total loss decrease with an increase in the rotational speed. In particular, the decrease in the amount of copper loss is large and the motor current decreases significantly. In the proposed motor, 


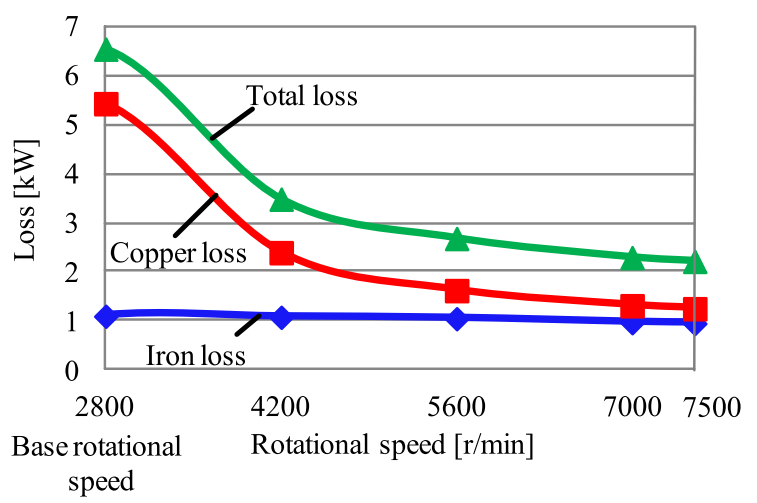

Fig. 19. Transition of total loss, copper loss, and iron loss of the proposed motor at constant power of $60 \mathrm{~kW}$ in region from $2800 \mathrm{r} / \mathrm{min}$ to $7500 \mathrm{r} / \mathrm{min}$

the magnetic flux generated by the motor current is dominant because the magnetic flux that the ferrite magnets generate is small. The motor current required for the flux-weakening operation is also small. Thus, the magnetic flux density of the proposed motor decreases with an increase in the rotational speed. Even if the rotational speed is increased, the iron loss does not increase. Hence, the point of maximum efficiency is reached at $7500 \mathrm{r} / \mathrm{min}$. At points of high efficiency where the rotational speeds are higher than the base rotational speed, the performance of the proposed motor exceeds that of the target motor using rare earth magnets.

\section{Conclusions}

This study introduced a $60 \mathrm{~kW}$ ferrite PM axial gap motor with a coreless rotor structure and investigated the detailed motor characteristics using 3D-FEA. It was found that the proposed motor achieved a maximum torque, maximum output power, maximum efficiency, and motor volume equal to those of the $60 \mathrm{~kW}$ motor in the third-generation Toyota Prius, which uses rare earth PMs. These outstanding attributes are the result of the axial gap configuration, the proposed coreless rotor structure, and the concentrated winding structure.

The areas of further improvement include the large cogging torque and the inability to accelerate up to the maximum rotational speed of the target motor. Future research should include methods for utilizing this motor's advantages, as well as improvements in design. In addition, we would like to conduct load and no-load experiments, and evaluate the proposed motor based on the experimental results.

\section{References}

( 1 ) S. Chino, T. Miura, M. Takemoto, S. Ogasawara, A. Chiba, and N. Hoshi: "Fundamental Characteristics of a Ferrite Permanent Magnet Axial gap Motor with Segmented Rotor Structure for the Hybrid Electric Vehicle", in Proc. 2011 IEEE Energy Conversion Congress and Exposition (ECCE 2011), pp.2805-2811 (2011)

( 2 ) M. Aydin, S. Huang, and T.A. Lipo: "Design, Analysis, and Control of a Hybrid Field-Controlled Axial-Flux Permanent-Magnet Motor", IEEE Trans. Ind. Electronics, Vol.57, No.1, pp.78-87 (2010)

( 3 ) C. Versele, Z. De Greve, F. Vallee, R. Hanuise, O. Deblecker, M. Delhaye, and J. Lobry: "Analytical Design of an Axial Flux Permanent Magnet InWheel Synchronous Motor for Electric Vehicle", in Proc. 2009 IEEE Int. EPE'09, pp.1-9 (2009)
( 4 ) Z. Wang, R. Masaki, S. Morinaga, Y. Enomoto, H. Itabashi, M. Ito, and S. Tanigawa: "Development of an Axial Gap Motor With Amorphous Metal Cores", IEEE Trans. Ind. Appl., Vol.47, No.3, pp.1293-1299 (2011)

( 5 ) K.M. Rahman, N.R. Patel, T.G. Ward, J.M. Nagashima, F. Caricchi, and F. Crescimbini: "Application of Direct-Drive Wheel Motor for Fuel Cell Electric and Hybrid Electric Vehicle Propulsion System", IEEE Trans. Ind. Appl., Vol.42, No.5, pp.1185-1192 (2006)

( 6 ) T.J. Woolmer and M.D. McCulloch: "Analysis of the yokeless and segmented armature machine", in Proc. 2007 IEEE Int. Electric Machines and Drives Conf. (IEMDC'07), pp.704-708 (2007)

( 7 ) P. Zheng, J. Zhao, R. Liu, C. Tong, and Q. Wu: "Magnetic Characteristics Investigation of an Axial-Axial Flux Compound-Structure PMSM Used for HEVs", IEEE Trans. Ind. Appl., Vol.46, No.6, pp.2191-2194 (2010)

( 8 ) M. Aydin, S. Huang, and T.A. Lipo: "A New Axial Flux Surface Mounted Permanent Magnet Machine Capable of Field Control," in Conf. Rec. 37th IEEE IAS Annu. Meeting, pp.1250-1257 (2002)

( 9 ) M. Aydin, S. Huang, and T.A. Lipo: "Torque Quality and Comparison of Internal and External Rotor Axial Flux Surface-Magnet Disc Machines", IEEE Trans. Ind. Electron., Vol.53, No.3, pp.822-830 (2006)

(10) C. Zhang, K.J. Tseng, and T.D. Nguyen: "Analysis and comparison of axial flux PM synchronous motor and induction motor", in Proc.2010 IEEE Int. IPEC2010, pp.572-577 (2010)

(11) S.L. Ho, S. Niu, and W.N. Fu: "Design and Analysis of a Novel Axial-Flux Electric Machine", IEEE Trans. Magnetics, Vol.47, No.10, pp.4368-4371 (2011)

(12) T.S. Kwon, S.K. Sul, L. Alberti, and N. Bianchi: "Design and Control of an Axial-Flux Machine for a Wide Flux-Weakening Operation Region”, IEEE Trans. Ind. Appl., Vol.45, No.4, pp.1258-1266 (2009)

(13) R. Al Zaher, S. de Groot, H. Polinder, and P. Wieringa: "Comparison of an axial flux and a radial flux permanent magnet motor for solar race cars", in Conf. ICEM2010, pp.1-6 (2010)

(14) A. Mahmoudi, H.W. Ping, and N.A. Rahim: "A Comparison between the TORUS and AFIR Axial-Flux Permanent-Magnet Machine Using Finite Element Analysis", in Conf. IEMDC2011, pp.242-247 (2011)

(15) Y. Ikeda, I. Iwata, T. Hatano, and J. Ishizaka: "Development and Manufacturing of High Strength and Toughness $18 \% \mathrm{Mn}-18 \% \mathrm{Cr}$ Retaining Ring Materials", Technical Report of Japan Steel Works, Ltd, No.46, pp.67-70 (1992) (in Japanese)

Kazuya Chiba (Student Member) was born in Hokkaido, Japan, in 1989. He received the B.S. degree in Electronics and Information Engineering from Hokkaido University, Hokkaido, Japan, in 2012. Since 2012, he has been studying toward the M.S. degree at Hokkaido University. He is engaged in research on permanent magnet synchronous motors for hybrid electric vehicles and their applications. Mr. Chiba is a student member of the Institute of Electrical Engineers of Japan.

Shinji Chino (Non-member) was born in Shiga Prefecture, Japan, in

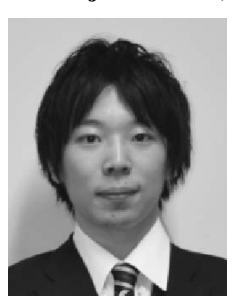
1987. He received the B.S. degree in Electronics and Information Engineering from Hokkaido University, Hokkaido, Japan, in 2010. Since 2010, he has been studying toward the M.S. degree at Hokkaido University. He is engaged in research on permanent magnet synchronous motors for hybrid electric vehicles and their applications. Mr. Chino is a student member of the Institute of Electrical Engineers of Japan. 
Masatsugu Takemoto (Member) was born in Tokyo, Japan, in 1972.

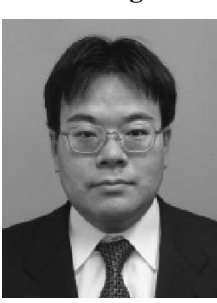

He received the B.S. and M.S. degrees in electrical engineering from the Tokyo University of Science, in 1997 and 1999, respectively. In 2005, he received the $\mathrm{Ph} . \mathrm{D}$. degree in electrical engineering from the Tokyo Institute of Technology. In 1999, he joined the Tokyo Institute of Technology, Tokyo, Japan, as a Research Associate in the Department of Electrical Engineering. In 2004, he joined the Musashi Institute of Technology, Tokyo, Japan, as a Research Associate in the Department of Mechanical Systems Engineering. From 2005, he was a Lecturer. In 2008, he joined the Hokkaido University, Hokkaido, Japan, where he is an Associate Professor with Division of Systems Science and Informatics. He is engaged in research on bearingless motors, permanent magnet synchronous motors, axial gap motors, and rare-earth-free motors.
Satoshi Ogasawara (Senior Member) was born in Kagawa Prefec-

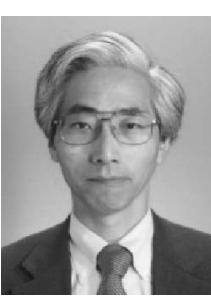
ture, Japan, in 1958. He received the B.S., M.S., and Dr.Eng. degrees in electrical engineering from Nagaoka University of Technology, Niigata, Japan, in 1981, 1983, and 1990, respectively. From 1983 to 1992 , he was a Research Associate with Nagaoka University of Technology. From 1992 to 2003, he has with the Department of Electrical Engineering, Okayama University, Okayama, Japan. From 2003 to 2007, he was with the Department of Electrical Engineering, Utsunomiya University, Utsunomiya, Japan. Since 2007, he has been a Professor in Graduate School of Information Science and Technology, Hokkaido University, Sapporo, Japan. His research interests are ac motor drive systems and static power converters. Dr. Ogasawara received the IEEE/PELS Society Prize Paper Award in 1999, and the IEEE/IAS Committee Prize Paper Awards in 1996, 1997, 2003 and 2010. He is a Senior Member of the Institute of Electrical and Electronics Engineers. 